\title{
Health Canada should license companies that mix drugs, says report
}

$\mathrm{H}$ ealth Canada should regulate businesses that mix drugs outside of licensed pharmacies, recommends an expert who investigated why 1202 patients, including 40 children, in Ontario and New Brunswick received diluted chemotherapy drugs between February 2012 and March of this year.

In the Ontario government-commissioned report, A Review of the Oncology Under-Dosing Incident, Jake Thiessen, founding director of the School of Pharmacy at the University of Waterloo, Ont., makes 12 recommendations to clarify who regulates what and to improve the supply chain that hospitals use to procure drugs."The entire incident was preventable," he writes in the report.

Thiessen says the current system has flaws at every level, from the governments, which are supposed to regulate pharmaceuticals, down to the hospitals that deliver them. Also implicated in this situation were Marchese Hospital Solutions, the company that mixed the drugs, and Medbuy, an organization that buys drugs in bulk for health care organizations in Ontario and New Brunswick.

The recommendations come four months after staff at a Peterborough, Ont. hospital realized that their chemotherapy drugs, cyclophosphamide and gemcitabine, supplied by Marchese, were diluted. Marchese provided the mixture to four hospitals in Ontario and one in New Brunswick.

Companies like Marchese have existed in a regulation void, with neither Health Canada nor the Ontario College of Pharmacists claiming responsibility for monitoring them.

According to the report, Marchese did not dilute the chemotherapy maliciously, or as a way to increase profit margins by skimping. Rather, the company did not account for individual bags of saline containing overfill, thus creating solutions of cyclophosphamide

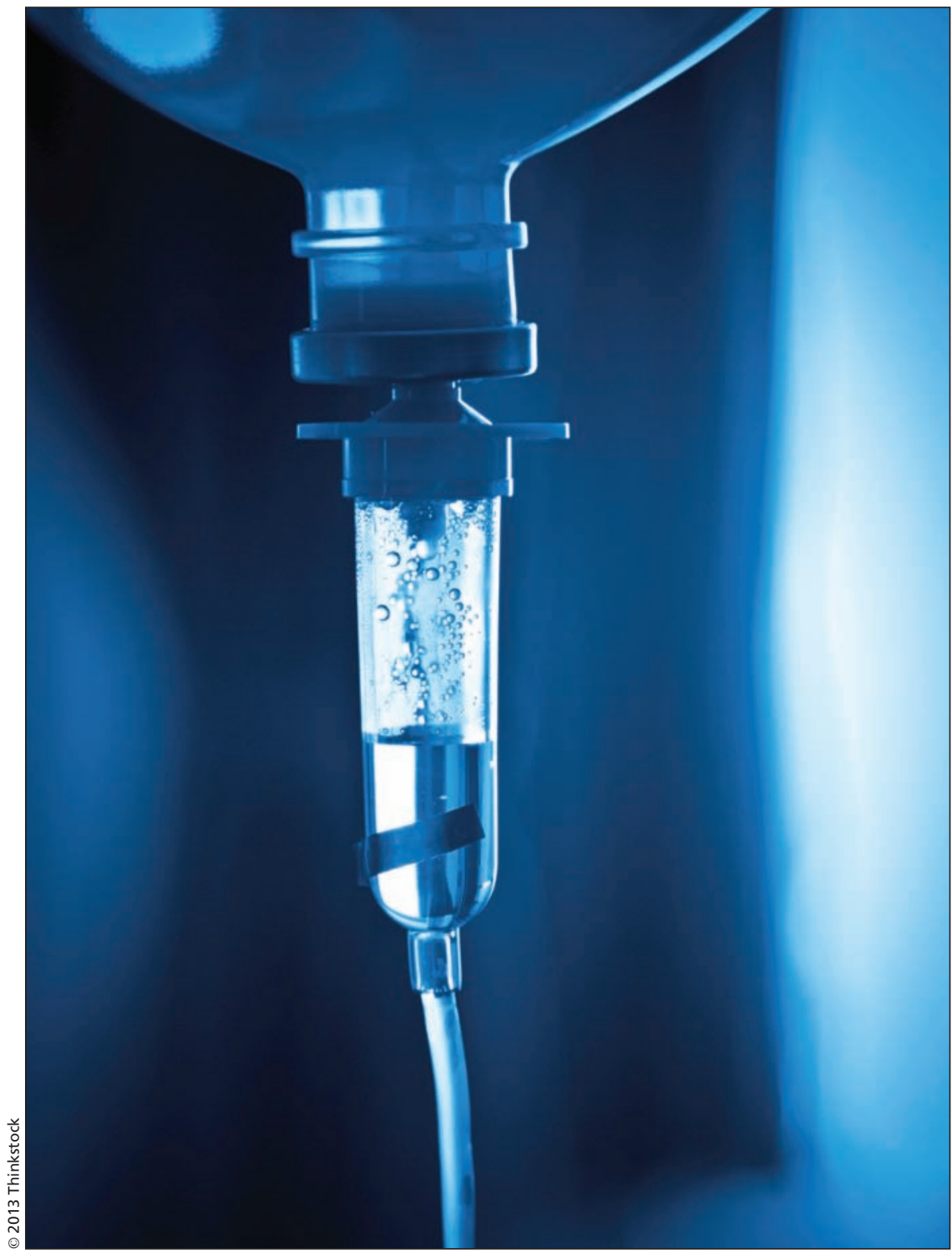

An Ontario government-commissioned report found that Marchese Hospital Solutions did not deliberately dilute the chemotherapy drugs received by over 1200 Canadians, but that the system through which hospitals get their drugs is flawed at every level.

and gemcitabine with concentrations that were on average $10 \%$ and $7 \%$ lower, respectively, than they should have been.

The report found that Marchese believed a single patient would use each bag, when in fact a bag can treat multiple patients. Medbuy's contract with Marchese tacitly supported this belief by not specifying a concentration for these drugs, but rather the amount of drug per bag of saline.

It's unlikely that the under-dosing did actual harm, Thiessen wrote, because the dosing shortfall could be considered within the ordinary tolerable 
margin of error, and in most cases the drugs were used in combination with other drugs.

"It's more than you would want to see, but in combination with the full dose of other drugs," potential harm should be mitigated, says Dr. Leonard Kaizer, Cancer Care Ontario's head of systemic treatment. Cancer Care is an Ontario government agency that drives improvement in disease prevention, screening and delivery of care.

In face-to-face interviews with patients who had received the diluted drugs, oncologists did not recommend additional treatment, which Kaizer says is a good sign. He says the report is "very balanced and reasonable from the perspective of a clinical oncologist."

Besides recommending that Health Canada regulate companies like Marchese, who mix drugs on a large scale and operate across provincial and territorial borders, Thiessen also recommends an expanded regulatory role for the Ontario College of Pharmacists. This would include licensing clinic and hospital pharmacies, and considering a special designation for licensed pharmacies that specialize in large-volume product preparation.

Ontario Health Minister Deb Matthews says she will introduce legislation in the fall authorizing the Ontario College of Pharmacists to license and inspect hospital pharmacies.

Cooperation with Health Canada has been "ongoing," says Lori DeCou, the college's communications manager.

"This incident brings focus around better definition between when authority should reside within Health Canada, in the federal domain, and where it might be more appropriate to reside within the provincial domain," she says.

Group purchasing organizations need to be more transparent and consider potential risks to patients as a key factor when awarding contracts, Thiessen writes. They also need to standardize their product specification descriptions to avoid ambiguity.

Health Canada has not said whether it will follow the report's recommendation that it regulate nonpharmacy drug mixers like Marchese, but stated in a press release that it "has been assessing the approaches being taken across the country to help inform any potential federal actions that may be needed to ensure proper oversight."

Marchese declined to comment outside of its online statement that it is "pleased" that the report found that the company supplied the drugs according to its contract, and did not dilute the drugs maliciously or deliberately.

A class-action suit was launched against Marchese days after the problem was disclosed. - Catherine Cross, CMAJ

CMAJ 2013. DOI:10.1503/cmaj.109-4573 